\title{
CHILE A CIEGAS, LA TRISTE REALIDAD DE NUESTRO MODELO ENERGÉTICO, DE RAÚL SOHR*
}

\section{Sebastián Püschel Løvengreen}

Cuando se discute la situación que encara Chile en relación a su desarrollo energético es difícil limitar la extensión de una reseña a unos cuantos párrafos, particularmente al enfrentar un libro que despliega una crítica dilatada y robustamente referenciada, debido a que sobreviene un sinnúmero de comentarios y reflexiones en torno a un tema de impacto transversal en nuestro país.

El desarrollo energético nacional -describe Raúl Sohr- ha seguido un curso equivocado y hemos alcanzado un punto crítico a la luz de los resultados que advertimos en la actualidad. El autor puntualiza enfáticamente que la semilla de esta situación es el modelo de desarrollo neoliberal, el cual ha apartado al Estado de la planificación energética desde principios de los años 80 . Esta realidad ha conducido a desajustes graves, dada la incapacidad del modelo de incorporar elementos de largo plazo de manera adecuada, quedando la planificación sistémica relegada a los resultados del albedrío de empresas cuyo afán es, por desgracia, cortoplacista y caprichosamente miope en el largo plazo.

Más allá de ser una obra que concentra mucha información relevante a la hora de encarar el debate sobre el desarrollo energético nacional, además de estar redactada y estructurada de manera que resulta en una lectura muy ágil, su autor es certero al seguir la estrategia de examinar el problema desde un enfoque político y, desde esa perspectiva, construir la tesis de que el modelo energético nacional está enfermo. Personalmente, suscribo a orientar la discusión en esa dirección, puesto que esgrimir argumentos técnicos para justificar los problemas del desarrollo energético nacional parece no tener lugar, y los argumentos económicos que se pueden emplear, en general, derivan de las reglas de juego impuestas a través del modelo, que es justamente el elemento que debe ser revisado desde una perspectiva política.

En cuanto a la estructura del libro, el autor describe el contexto energético nacional y presenta su tesis a través del desarrollo de cuatro grandes ejes: la realidad de nuestro modelo energético, la caracterización de las energías renovables no convencionales a nivel nacional e internacional, la posición de Chile frente a la energía nuclear y la delicada situación alcanzada a nivel mundial a la luz del cambio climático y su relación con el uso intensivo de combustibles fósiles en los últimos siglos. Las razones que justifican este ordenamiento pueden emanar a la luz del escrutinio interno de la realidad energética nacional, así como del examen del contexto externo: internamente, Chile cuenta con la gran fortaleza de disponer de un alto potencial de energías renovables no convencionales, sin embargo, se exhibe un débil esquema de ordenamiento del mercado eléctrico a la hora de enfrentar los nuevos desafíos energéticos. Al abrirse a la alternativa

* Sohr, R., Chile a ciegas. La triste realidad de nuestro modelo energético, Santiago: Random House Mondadori, $3^{a}$ ed., octubre 2012. 
de los grandes proyectos nucleoeléctricos, el país se demuestra frágil por la naturaleza sísmica de nuestro territorio. En cuanto al contexto externo, se presentan las latentes amenazas del cambio climático y la dependencia del tenso, políticamente inestable y decimonónico mercado de los combustibles fósiles. No obstante, de la búsqueda por volverse inmune a estos peligros nace la gran oportunidad que tiene Chile: transformarse en un referente asociado a una o más tecnologías ERNC, gracias a su idóneo potencial energético y a la existencia de las capacidades técnicas para concretarlo.

Si bien no es una idea nueva, la oportunidad presentada antes es muy potente puesto que derriba la noción de sobrecostos sociales que subyace tras la idea de alcanzar la diversificación de la matriz, la independencia energética y el desarrollo limpio a través del desarrollo de energías renovables, transformando así un trade-off en un trade-on: la entrega de energía diversa, limpia e independiente no tiene por qué representar una carga para la sociedad, si se consideran todos sus beneficios y se captura la oportunidad de iniciar desarrollo tecnológico local y generar valor agregado en un país con el potencial necesario para hacerlo. ¿Qué falta? Percibir la oportunidad y capturarla. ¿Quién debe hacerlo? Raúl Sohr piensa que es el Estado quien debe asumir la responsabilidad de coordinar activamente estos esfuerzos.

Es relevante precisar que el principio de subsidiariedad establece una jerarquía entre los actores que deben proveer los productos y servicios que requiere el país, siguiendo una estrategia bottom-up en la toma de decisiones: primero el emprendimiento de los individuos, luego, asociaciones locales voluntarias, continuando con los gobiernos regionales y así sucesivamente hasta llegar al Estado, si los sujetos previos no demuestran el interés o la capacidad de hacerlo de manera correcta. El diagnóstico del autor es que el emprendimiento individual no ha resultado efectivo en el contexto del desarrollo energético. Chile parece tener músicos capaces, pero a juicio del autor son muy pocos y, además, hace falta un director de orquesta que marque el tempo a través del ordenamiento territorial consensuado, licitación de proyectos de generación, o tantos otros caminos que se podrían recorrer. Es efectivo que, a través de modificaciones regulatorias, el Estado chileno podría actuar como director de orquesta, sin embargo, a juicio personal, parece natural recalcar que al menos sería necesario el involucramiento de una sociedad seria e informada en el problema del desarrollo energético, de modo de garantizar la fiscalización al ente coordinador, con tal que este director sienta la presión de presentar ante un público entendido y examinador, a la vez que los oyentes comprendan cuán complejo es dirigir.

Muchos países han sido capaces de dar los golpes de timón necesarios para transformar el desafío del desarrollo energético en una oportunidad. Muchos de ellos operan con sistemas más o menos liberalizados y obtienen variados resultados, lo que demuestra que no hay una receta única. Chile enfrenta la inigualable posibilidad de cambiar las cosas en sentido positivo en materia energética, pero para aprehender esta oportunidad hoy apremia vencer la enorme inercia que siempre hemos tenido al realizar modificaciones en aquellas áreas que, a pesar de funcionar, podrían hacerlo muchísimo mejor. 